1 Newman PK, Saunders M. Lithium neurotoxicity. Postgrad Med J 1979;55:701-3.

2 Brust JCM, Hammer JS, Challenor Y, et al. Acute generalised polyneuropathy accompanying lithium poisoning. Ann Neurol panying lith

3 Uchigata $M$, Tanabe $H$, Hasue I, et al. Peripheral neuropathy due to lithium intoxication. Ann Neurol 1981;9:414.

4 Pamphlett RS, MacKenzie RA. Severe peripheral neuropathy due to lithium intoxication. J Neurol Neurosurg Psychiatry 1982;45:656.

5 Chang YC, Yip PK, Chiu YN, et al. Severe generalised polyneuropathy in lithium intoxication. Eur Neurol 1988;28:39-41.

6 Vanhooren G, Dehaene I, Van-Zandycke M. et al. Polyneuropathy in lithium intoxication. Muscle Nerve 1990;13:204-8.

7 Zochodne DW, Bolton CF, Wells JJ, et al. Critical illness polyneuropathy. A complica Critical ilness polyneuropathy. A complica1987;110:819-42.

8 Schou M, Baastrup PC, Grof P, et al. Pharmacological and clinical problems of lithium prophylaxis.

9 Baldessarini RJ, Lipinski JF. Lithium salts: 1970-1975. Ann Int Med 1975;83:527-33.

10 Girke W, Krebs FA, Muller-Oerlinghauser H, et al. Effects of lithium on electromyographic recordings in man: studies in manicdepressive patients and normal volunteers. Int Pharmacopsychiatry 1975;10:24-36.

\section{Bulimia in a patient with temporal lobe} epilepsy

There have been no reports of focal neuroanatomical lesions associated with bulimia nervosa. The following is a case report of a patient with bulimia, who was found to have a lesion of the left temporal lobe on MRI during evaluation for a seizure disorder.

The patient was a 33 year old right handed female college administrator who had complained of fainting spells since the age of six. These had occurred at least once or twice a year and, after puberty, often five to seven days premenstrually. She came to neurological attention after having had three such spells in four months. During one of these recent episodes rhythmical twitching of the right hand had been observed.

She typically experienced an aura of a strong odour of ether lasting up to one minute before each event, followed by unconsciousness for about 30 seconds. Infrequently she also had experienced nocturnal bladder incontinence as a child and as an adult.

An eating disorder with onset at the age of 28 had been diagnosed as bulimia nervosa. Since that time she had been having recurrent periods of daily binge-eating behaviour followed by self-induced vomiting which would last for up to a year, followed by periods of remission lasting four to six months.

Despite feeling loss of control over her eating behaviour, she was always aware of her actions and had never experienced amnesia, somnolence, or syncope during the binges or purges. She generally maintained her weight in the normal range of $55-60 \mathrm{~kg}$ with a maximum weight fluctuation of $14 \mathrm{~kg}$. The severity of the behaviour had increased during the couple of months preceding the time of presentation.

There had also been alcohol abuse up until five years ago. There was no history of depression. The family history included the father who had alcoholism and a paternal cousin with multiple sclerosis.

Her neurological and general examination were normal. Her mood was not depressed. A sleep deprived EEG showed a burst of theta slow waves in the left temporal leads during the awake state. An MRI of the brain showed a lesion in the left temporal lobe adjacent to the medial tip of the lateral ventricle in the region of the hippocampus. This was felt to represent a cystic dilatation of the ventricle or a small area of infarction (figure).

The patient was treated with carbamazepine. During the 18 months of treatment, she has had no further olfactory hallucinations, seizures, or syncopal episodes. She has had one episode of nocturnal incontinence. Her eating habits have been under good control and her weight has been stable. There have been no eating binges, purging, or feelings of compulsion to fast or eat large quantities of food.

This patient demonstrates a possible pathogenic relationship of temporal lobe disease to bulimia. Although the cause and pathogenesis of bulimia remain unknown, in addition to psychological factors, biological factors appear to play a role in the disorder.

Hyperphagia has been described in some neurological disorders including Huntington's disease, amygdalectomy, frontal and hypothalamic tumours, frontal lobotomy, Pick's disease, epilepsy, Kleine-Levin syndrome, and von Economo's encephalitis. Hyperphagia in such patients, however,
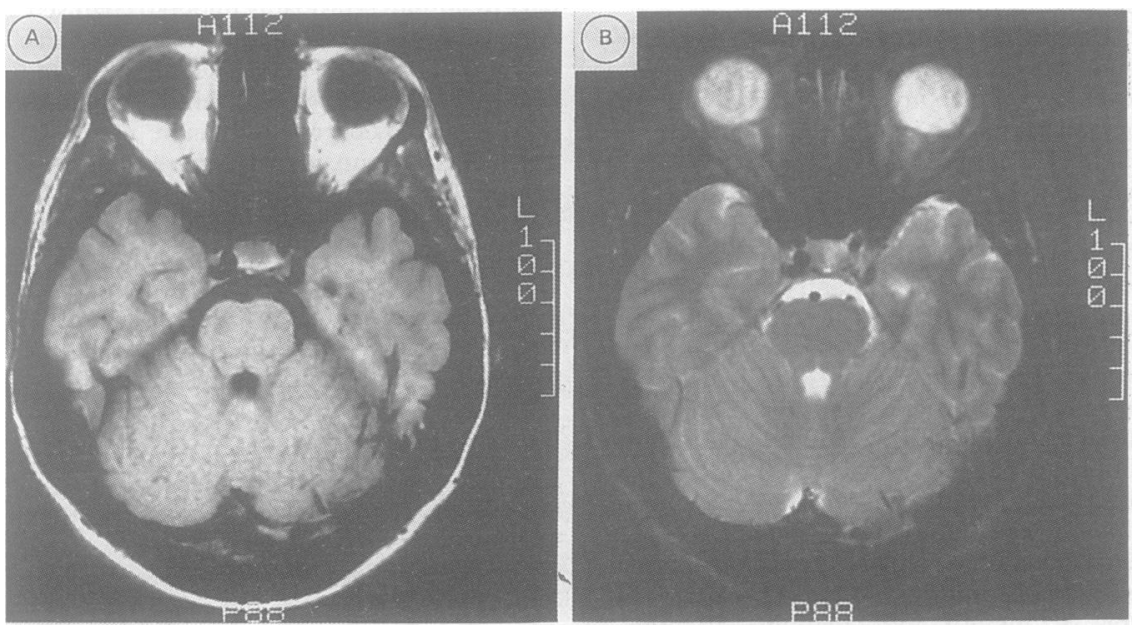

Figure MRI axial views showing $A$ ) low signal area in the medial left temporal lobe on $T_{1}$-weighted image $(T R=857 \mathrm{~ms}, T E=20 \mathrm{~ms})$ and $\left.B\right)$ high signal area in the same region on $T_{2}$-weighted image $(T R=3243 \mathrm{~ms}, T E=80 \mathrm{~ms})$. clearly differs from the binge-purge diathesis seen in bulimia. Furthermore, bulimic patients tend to be selective in their eating behaviour, unlike the Kluver-Bucy syndrome, and maintain a normal weight. Aside from the relatively late onset of bulimia, this patient displays the behaviour, feelings, and clinical course typical of the more specific disorder of bulimia nervosa.

Studies of patients with bulimia nervosa using CT have reported ventricular dilation and sulcal enlargement; however, focal brain disease has not been demonstrated. MRI is a more sensitive technique for the detection of temporal lobe lesions in epilepsy, which could be of potentially greater yield in showing lesions in patients with eating disorders, as was seen in this case.

The temporal lobes have an integrative role in forming the brain's body image via afferent information from secondary sensory areas and the limbic system. Structural or biochemical disease of this part of the brain could thus play a role in the distorted self image which occurs in bulimia.

Reports of EEG abnormalities in bulimia range from $16-64 \%$, depending mainly upon the diagnostic criteria used for EEG abnormality. In the series of 23 patients with compulsive eating treated by Rau and Green, a positive response to phenytoin was correlated with those patients having a combination of abnormal EEG plus other neurological symptoms such as dizziness or rage attacks. ${ }^{1}$ A modest response to phenytoin was seen in a later double blind, placebocontrolled study of 20 patients; however, response was not correlated with pretreatment EEG abnormality. ${ }^{2}$ Subsequent case studies of phenytoin treatment were less positive, and enthusiasm for anticonvulsant treatment of bulimia waned.

Epilepsy has yet to be conclusively demonstrated as a direct cause of bulimia. Disturbances of body perception are known to occur as experiences in patients with temporal lobe epilepsy, as well as compulsive water drinking and ictal vomiting. Ictal eating has not been reported; however, eating has been reported as a reflex cause of epilepsy, with seizures being most often complex partial in type and related to temporal lobe foci. ${ }^{3}$ Also, Remick reported three patients with postictal hyperphagia.

The relationship of bulimia and temporal lobe epilepsy in this case is that of an interictal behaviour. The response of abnormal eating behaviour to carbamazepine in this patient could have been related to suppression of limbic kindling in the hypothalamus by the seizure focus.

Treatment of bulimia with carbamazepine has been reported in a double-blind crossover trial of six patients, of whom one showed a dramatic response to carbamazepine. ${ }^{5}$ This patient also had an associated mood disorder. A patient with bulimia, depression, and amnesic episodes with an EEG showing diffuse paroxysmal activity has also been reported to improve with carbamazepine treatment. ${ }^{6}$

The possibility that the temporal lobe lesion and secondary epilepsy in this patient were coincidentally related to bulimia cannot be excluded. The observations that her epilepsy worsened and came to attention during a flareup of bulimic behaviour and that both problems went into prolonged remission simultaneously with anticonvulsant therapy suggest a significant relationship. Furthermore, carbamazepine seems to be of potential 
benefit in the treatment of bulimia and deserves consideration for future placebo controlled study.

$$
\begin{array}{r}
\text { BRIAN R OTT } \\
\text { Department of Neurology, } \\
\text { Roger Williams General Hospital, } \\
\text { Brown University, } \\
\text { Providence, RI, USA }
\end{array}
$$

Providence, RI, USA

1 Rau JH, Green RS. Soft neurological correlates of compulsive eaters. $J$ Nervous and Mental Dis 1978;166:435-7.

2 Wermuth BM, Davis KL, Hollister LE, Stuunkard AJ. Phenytoin treatment of the binge-eating syndrome. Am J Psychiatry 1977;134:1249-53.

3 Koul R, Koul S, Razadan S. Eating Epilepsy. Acta Neurol Scand 1989;80:78-80.

4 Remick RA, Jones MW, Campos PE. Postictal Bulimia (letter). J Clin Psychiatry 1980; 41:256.

5 Kaplan AS, Garfinkel PE, Darby PL, Garner DM. Carbamazepine in the treatment of bulimia. Am J Psychiatry 1983;140:1225-6.

6 Signer SF, Benson DF. Three cases of anorexia nervosa associated with temporal lobe epilepsy. Am J Psychiatry 1990;147:235-37.

Non tumoural aqueductal stenosis with intermittent course. Case report after a six year follow up.

The aetiology of non tumoural aqueductal stenosis presenting in adults remains unknown in most cases. ${ }^{1}$

Rarely it can occur either as a sequela of neonatal or infantile meningitis, congenital toxoplasmosis or viral infection, ${ }^{2}$ in a genetically determined pattern with an $\mathrm{x}$-linked recessive trait often as part of a malformative syndrome. ${ }^{34}$ It can also occur in a congenital form coexisting with other CNS malformation. $^{2}$

The clinical picture is extremely varied ranging from symptom-free cases, with hydrocephalus and aqueductal stenosis being an accidental necropsy finding, ${ }^{5}$ to a sudden onset of progressive neurological deterioration. ${ }^{6}$

A minor skull trauma, a febrile illness, a subarachnoid haemorrhage, or even a lumbar puncture can precipitate an acute disturbance of cerebrospinal fluid dynamics with a complex clinical picture.

On 22 May 1981 a 12 year old male suffered a skull trauma without loss of consciousness or fractures and presented with a severe headache with nausea and vomiting lasting one week. CT scan showed a slight ventricular dilatation.

He presented with a parental migraine and a past history characterised by recurrent attacks of migraine-like headaches without aura. From the age of 13 the patient experienced episodes characterised by the sudden onset of headache, nausea, vomiting, sleepiness and gaze abnormality. These episodes lasted two to five days and occurred up to once a month. He had experienced nine episodes before admission.

On 30 March 1983 when he was 14 years he was admitted to the Neurological Department of Bologna University with headache, vomiting and stupor.

Neurological examination revealed defective upward gaze, skew-deviation and very sluggishly reacting mydriatic pupils. Routine blood and urine analyses were normal. EEG showed a spindle coma pattern. CT scan with
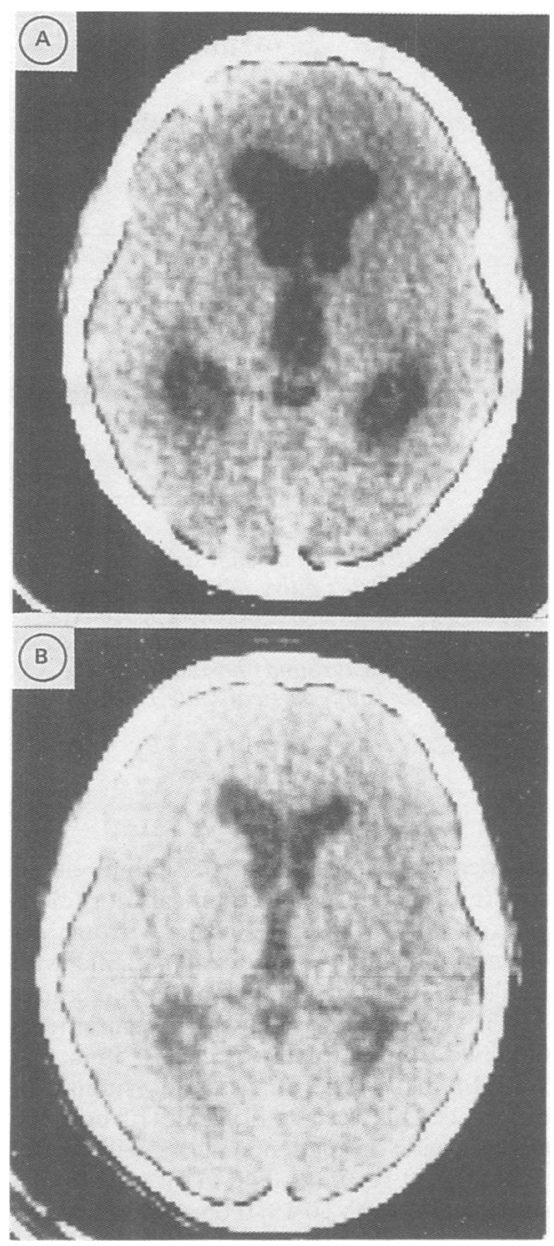

Figure 1a CT scan performed on 30 March 1983: lateral ventricles and the third ventricle are considerably dilated. $16 C T$ scan on 30 April 1983: slight reduction of the threeventricular hydrocephalus.

sciousness, directly related to an intermittent three-ventricular hydrocephalus.

After a minor skull trauma suffered at the age of 12 years, an intermittent clinical course started with recurring episodes with gradual spontaneous remission.

Neuroradiological studies over a period of six years performed during the acute phase and interictally, revealed an intermittent aqueductal stenosis.

The clinical course of non neoplastic aqueductal stenosis in adulthood is described as a chronic process with a fast or slow evolution. Cases with obstructive hydrocephalus and an intermittent clinical course were only seen with intermittent obstruction of the ventriculo-peritoneal or ventriculo-atrial shunt, ${ }^{7}$ in spontaneous ventriculostomy ${ }^{6}$ and in Arnold Chiari malformation. ${ }^{8}$

We agree with Williams ${ }^{910}$ who analysed the pathogenesis of benign aqueductal stenosis and stressed that hydrocephalus precedes and is usually the most important cause of the narrowing or blockage of the aqueduct.

Our patient had a cranial trauma precipitating an acute disturbance of cerebrospinal fluid dynamics. This factor together with slight physiological increases in intracranial pressure, usually well compensated, might cause a progressive enlargement of the ventricular system. As hydrocephalus progresses the third ventricle shows a tendency to enlarge progressively and the massa intermedia becomes stretched. ${ }^{10} \mathrm{~A}$ further increase in cerebrospinal fluid pressure in our patient could force open the aqueduct with the restoration of normal flow and rapid remission of the clinical symptoms.

MASSIMO GALEOTT PIERO DE CAROLIS
TOMMASO SACQUEGNA Neurological Service, Ospedale Maggiore, Bologna Neuroradiological Service, Ospedale Bellaria, Bologna, Italy

Correspondence to: Dr Sacquegna.

contrast enhancement demonstrated a conspicuous three-ventricular hydrocephalus (fig 1a). On the fourth day pneumoencephalography confirmed the hydrocephalus and a subsequent ventriculography showed a hypertrophy of the massa intermedia in the third ventricle, which was dilated. Bilateral carotid angiography was negative. SabinFeldman dye test and serological test for cisticercosis were negative. Eight days after admission the patient was asymptomatic and the EEG was normal.

One month later, a CT scan demonstrated a slightly shrunken hydrocephalus (fig 1b). After being discharged, he experienced an initial three month symptom-free period followed by episodes at first once a month, then once every three months.

On 13 November 1984, MRI scans were performed during the acute event showing a remarkable three-ventricular hydrocephalus with an important aqueductal stenosis. Two months later the patient was asymptomatic.

Over the past four years the episodes have occurred as infrequently as once a year with a spontaneous remission. Currently, neurological examination and neuropsychological tests are normal. The last CT, performed on 12 March 1989, showed a slight ventricular dilatation.

Our patient showed transient signs and symptoms of aqueductal stenosis such as Parinaud's syndrome and disturbance of con-

Hirsch JF, Hirsch E, Sainte Rose CH, Renier D, Pierre-Kyan A. Stenosis of the Aqueduct of Sylvius. Etiology and treatment. J Neurosurg Sci 1986;30:29-39.

2 Jellinger $G$. Anatomopathology of non-tumoral aqueductal stenosis. J Neurosurg Sci 1986; 30:1-16.

3 Bickers DS, Adams RD. Hereditary Stenosis of the Aqueduct of Sylvius as a cause of congenital hydrocephalus. Brain 1949;72:246-62.

4 Edwards JH, Norman RM, Roberts JM. Sexlinked Hydrocephalus: Report of a Family with 15 affected members. Arch Dis Child 1961;36:481-5.

5 Mc Hugh PR. Occult Hydrocephalus. Quart J Med 1964;33:297-308.

6 Wilkinson HA, Lemay M, Drew JH. Adult Aqueductal Stenosis. Arch Neurol 1966; 15:643-8.

7 Balakrishnan V, Dinning TAR. Non-Neoplastic Stenosis of the Aqueduct Presenting in Adolescence and Adult life. Surgical Neurology 1977;7:333-8.

8 Vrabec TR, Sergott RC, Savino PJ, Bosley TM. Intermittent Obstructive Hydrocephalus in the Arnold Chiari Malformation. Ann Neurol 1989;26:401-4.

9 Williams B. Is Aqueduct Stenosis a result of Hydrocephalus? Brain 1973;96:399-412.

10 Williams B. Aqueduct Stenosis. In: Smith WT, Cavanagh JB, eds. Recent advances in neuropathology, vol 2. Edinburgh: Churchill Livingstone, 1982:273-96. 